\title{
TATAR TÜRKÇESİ YAZI DİLİNDE VE AĞIZLARINDA y-/c- SESİ ÜZERINE*
}

\author{
Ercan ALKAYA**
}

\begin{abstract}
Özet
Türkçede ön seste y- sesinin korunması veya c-, j- gibi seslere dönüşmesi ilginç bir görünüm arz eder. $y->c-/ j-$ dönüşümü bir Kıpçak dil özelliği olarak kabul edilmekte ve günümüzde Kıpçak Türkçesinin çağdaş temsilcilerinde görülmektedir. Ancak Kıpçak grubu Türk lehçelerinde de ön sesteki bu kullanım farklılık arz eder. Ön ses y-, günümüz Kıpçak Türk lehçelerinden Kırgız, Karaçay-Balkar Türkçelerinde c-; Kazak, Karakalpak Türkçelerinde ise jolarak görülürken, Başkurt, Nogay, Kırım-Tatar, Kumuk, Karay Türkçelerinde ise değişikliğe uğramaz. Oğuz (Türkiye, Azerbaycan, Türkmen, Gagauz) ve Karluk (Özbek, Uygur) grubu Türk lehçelerinde de ön seste y- korunmaktadır. Kuzeydoğu grubu Türk lehçelerinden Tuva ve Hakas Türkçelerinde ç-, Altay Türkçesinde de c-'dir. y- sesi Yakutçada (Saha) s-, Çuvaşçada da ş- olmaktadır. Ön seste y-/c- sesinin durumu bakımından Tatar Türkçesi farklı bir görünüm arz etmektedir. Tatar Türkçesinde sayı olarak ön seste y- 'yi koruyan kelimeler çoğunlukta olsa da (yafrak "yaprak", yakın, yıl, yalkın "alev", yat-, yıl gibi), önemli bir miktarda da ön seste cbulunduran kelimeler yer almaktadır. Tatar Tílinin Ajlatmalı Süzligi’’nde (C.III, Kazan 1981)

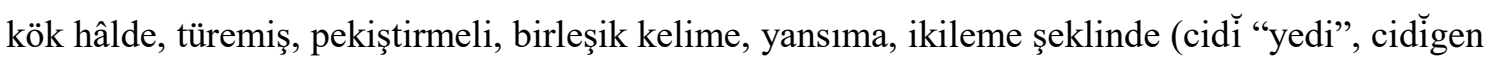
"yedigen”, cidiyıllık “yedi yıllık", cinel "hafif”, ciniley- "hafifle-", cir "yer", cir-kük "yer gök”,

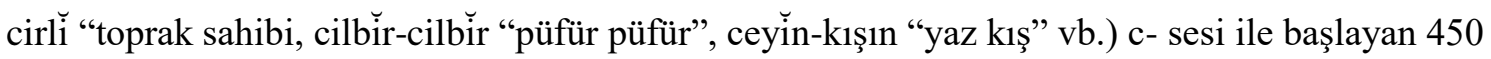
civarında Türkçe madde başı kelime bulunmaktadır.

Tatar yazı dilinde diğer Türk lehçelerinden farklılık arz eden y->c- değişmesi bilhassa /i/ ünlüsünden önce cil "yel", cir "yer" gibi kelimelerde ortaya çıkmakta ve bu durum diğer Kıpçak lehçelerinin Tatar Türkçesine tesiriyle açıklanmaktadır. Ancak gerek Tatar Türkçesinin tarihî dönemleri gerekse ağızları dikkate alınırsa, Tatar Türkçesindeki ön ses y->c- değişiminin diğer Kıpçak lehçelerinin etkisinden ziyade kendi yapısı ve şartları göz önünde tutularak değerlendirilmesi gerekliliği ortaya çıkmaktadır. Bu çalışmada da Tatar Türkçesinin tarihî metinleri ve ağızları incelenerek söz konusu durum hakkında bir değerlendirme yapılacaktır. Bu bağlamda Orta (Kazan), Batı (Mişer), Doğu (Sibirya) gibi üç büyük ağız grubu olan Tatar Türkçesinin ağızlarından ve yazı dilinden örnekler verilecek, ön ses y-'nin ilgili ağızlarda korunması veya başka seslere dönüşmesi değerlendirilecektir.
\end{abstract}

Anahtar Kelimeler: Tatar Türkçesi, Tatar Yazı Dili ve Ağızları, Kıpçak Türkçesi, y-/csesi.

\section{ON THE INITIAL y-/c- IN TATAR TURKISH WRITTEN LANGUAGE}

\begin{abstract}
In turkish, the preservation of initial $y$ - or its alteration with $c-, j$ - expopses an interesting feature. The alteration of $y->c-/ j-$ is accepted to be an Kipchak feature and seen in the modern representatives of Kipchak Turkish. But, initial y-, while seen as c- in Kirghiz and Karachay- Balkar and as j- in Kazakh and Karakalpak, doesnt not change in Bashkir, Noghai, Crimea-Tatar, Kumyk and Karai Turkish. Initial y- is also preserved in Oghuz (Turkey,

\footnotetext{
* Bu makale, 22-26 Mayıs 2017'de Ankara'da Türk Dil Kurumu tarafindan düzenlenen 8. Uluslararası Türk Dili Kurultayı'na sunulmuş bildirinin yeniden gözden geçirilmiş ve düzenlenmiş biçimidir.

** (Prof. Dr.) Fırat Üniversitesi, İnsani ve Sosyal Bilimler Fakültesi, Çağdaş Türk Lehçeleri ve Edebiyatları Bölümü, ELAZIĞ, El-mek: ealkaya16@gmail.com
} 
Azerbaijan, Turkoman and Gagauz) and Karluk (Uzbek, Uighur) language groups. In Northeastern language group, initial $\mathrm{y}$ - is ç- in Tuva and Khakas and c in Altai Turkish; in Yakutian s- and in Chuvash ş́-. Tatar Turkish has a different feature in terms of the situation of the initial y-/c-. Eventhough the number of the words which preserved initial y- (yafrak "leaf", yakın "near, close", y1l "year", yalkın "fire", yat- "to sleep, to lie down") are the majority, the number of which changed it into c- are substantial. There are 450 headwords with intial c- in the forms of base, derived, intensive, compound, mimetic, handiadyoin (cid “ "seven", cidigen "heptagon", cidiy1ll1k "for seven years", cinel "slight, light", cijiley- "to get light-", cir

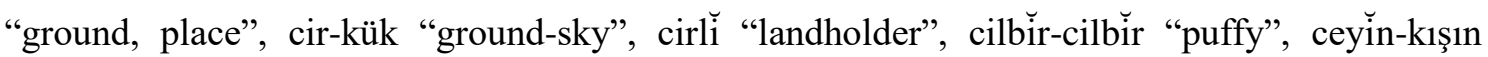
"summertime-wintertime" vb.) in the Tatar Language Descriptive Dictionary (V. III, Kazan 1981).

In Tatar written language the above-cited differential alteration of $y-/ c-$ occurs specially when preceding /i/ like in cil "wind", cir "ground, place" and this change is considered to occur as a consequence of the effect of the other Kipchak dialetcs. Considering historical periods and sub-dialects of Tatar Turkish, initial y-/c-alteration in Tatar Turkish should be examined by taking into account its own structure and circumstances rather than the influence of Kipchak dialects. In this context, by giving examples from three major subdialetcs of Tatar Turkish, Center (Kazan), West (Misher), East (Siberia), and Tatar written language, the preservation and alterqation of initial $\mathrm{y}$ - will be eloborated. y-/c- sound.

Key Words: Tatar Turkish, Tatar Written Language and Subdialects, Kipchak Turkish,

Türkçede ön seste y- sesinin korunması veya c-, j- gibi seslere dönüşmesi ilginç bir görünüm arz eder. $y->c-/ j-$ dönüşümü bir Kıpçak dil özelliği olarak kabul edilmekte ve günümüzde Kıpçak Türkçesinin çağdaş temsilcilerinde görülmektedir ${ }^{1}$. Ancak Kıpçak grubu Türk lehçelerinde de farklılık arz eder. Ön ses y-, günümüz Kıpçak Türk lehçelerinden Kırgız, Karaçay-Balkar Türkçelerinde c-; Kazak, Karakalpak Türkçelerinde ise j- olarak görülürken, Başkurt, Nogay, Kırım-Tatar, Kumuk, Karay Türkçelerinde ise değişikliğe uğramaz. Oğuz (Türkiye, Azerbaycan, Türkmen, Gagauz) ve Karluk (Özbek, Uygur) grubu Türk lehçelerinde de ön seste y- korunmaktadır. Kuzeydoğu grubu Türk lehçelerinden Tuva ve Hakas Türkçelerinde ç-, Altay Türkçesinde de c-' dir $^{2}$. y- sesi Yakutçada (Saha) s- (Kirişçioğlu, 2007: 1238), Çuvaşçada da ş́- (Ersoy, 2007: 1292) olmaktadır. Ön seste y-/c- sesinin durumu bakımından Tatar Türkçesi farklı bir görünüm arz etmektedir. Tatar Türkçesinde sayı olarak ön seste y-'yi koruyan kelimeler çoğunlukta olsa da, önemli bir miktarda da ön seste c- bulunduran kelimeler yer almaktadır.

\footnotetext{
${ }^{1}$ Ön ses y->c-/c- dönüşümü başka dillerde de görülen bir ses olayıdır. V. A. Bogoroditskiy, Türkçedeki /y/ sesinin İdil-Ural Tatar Türkçesinde /c/ye, Kazak Türkçesinde /j/ye dönüşmesi gibi, Latin halk dilindeki /y/ sesinin de İtalyancada /dj/'ye, Fransızcada da /j/ye değiştiğini belirtmektedir. bk. EXETOV, G. X., Tatar Dialektologiyes ${ }^{o}$, Kazan 1984, s. 45.

${ }^{2}$ Kıpçak, Karluk ve Kuzeydoğu Türk lehçelerinde ön ses y-'nin durumu için bk. BURAN, Ahmet - Ercan ALKAYASüleyman Kaan YALÇIN (2014), Çăgdaş Türk Yazı Dilleri I, Güneybatı/Oğuz Grubu, Akçağ Yay., Ankara; BURAN, Ahmet - Ercan ALKAYA (2014a), Çağdaş Türk Yazı Dilleri II, Güneydoğu/Karluk Grubu, Akçağ Yay., Ankara; BURAN, Ahmet - Ercan ALKAYA (2014b), Çağdaş Türk Yazı Dilleri III, Kuzeybatı/Kıpçak Grubu, Akçağ Yay., Ankara; BURAN, Ahmet - Ercan ALKAYA-Mehmet ÖZEREN (2014), Çağdaş Türk Yazı Dilleri IV, Kuzeydoğu Grubu, Akçağ Yay., Ankara.
} 
Türk lehçelerinde ön ses y-'nin görünümünü şöyle bir tabloyla gösterebiliriz:

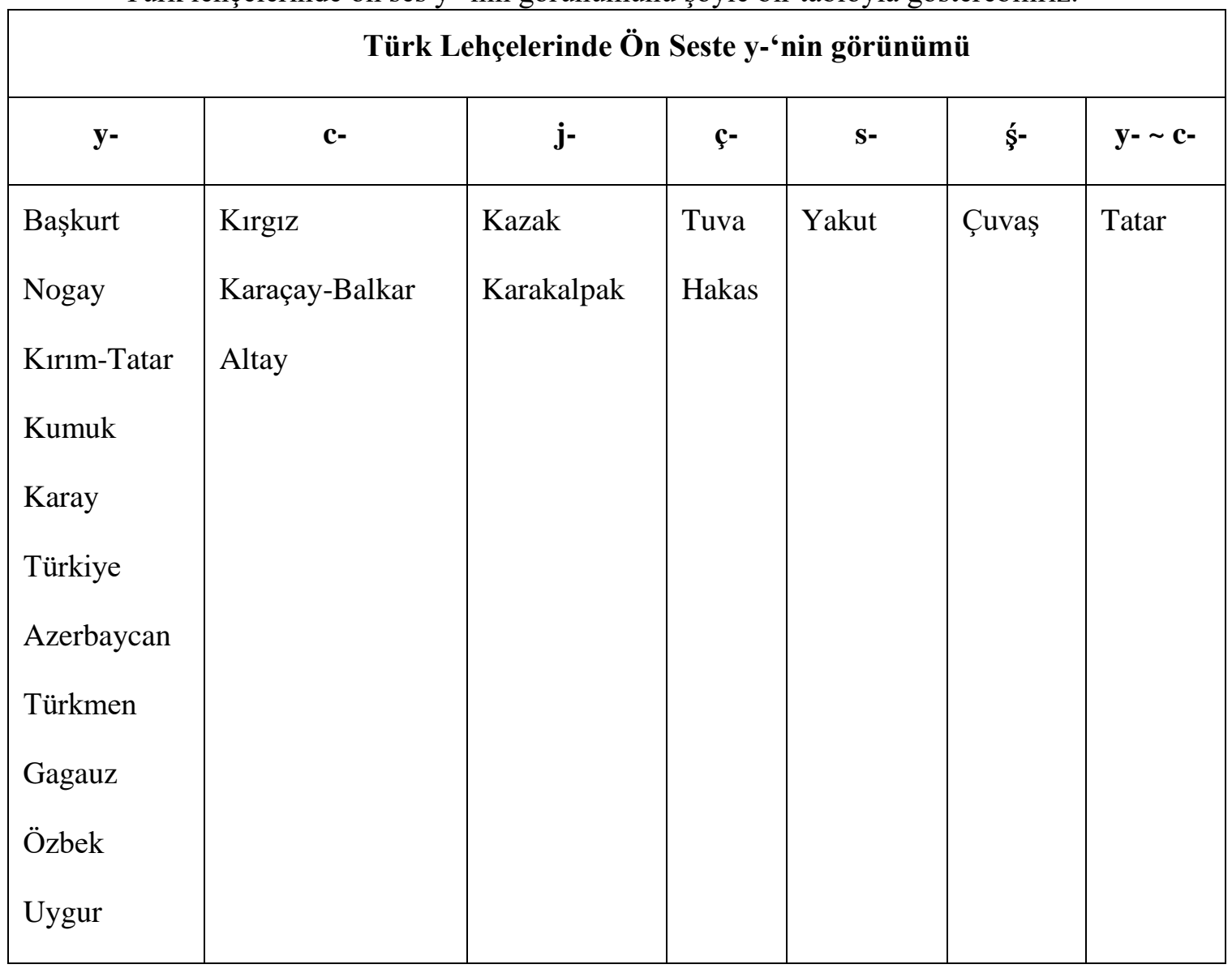

Tatar Türkçesinin yazı dilinde Türkçe kelimelerde ön seste çoğunlukla y- sesi korunurken azımsanamayacak kadar kelimede de y->c- dönüşümü bulunmaktadır. Tatar Tílinin Aylatmalı Süzlïgi’'nde (C. III, Kazan 1981) kök hâlde, türemiş, pekiştirmeli, birleşik kelime, yansıma, ikileme şeklinde (cidi “yedi”, cidigen “yedigen”, cidiyıllık "yedi yıllık”, cinel "hafif”, ciniley- "hafifle-", cir "yer”, cir-kük "yer gök”, cirli “toprak sahibi, cilbï-cilbir "püfür püfür”, ceyin-kışın "yaz kış" vb.) c- sesi ile başlayan 450 civarında Türkçe madde başı kelime bulunmaktadır. Bu kelimelerin de büyük çoğunluğu i, $\breve{i}$, e, ü (bilhassa i) gibi ince sıradan ünlülerden önce (cil "yel”, cidi "yedi”, cir "yer", cim "yen”, cinil "hafif”, cit- "yet-", cinge

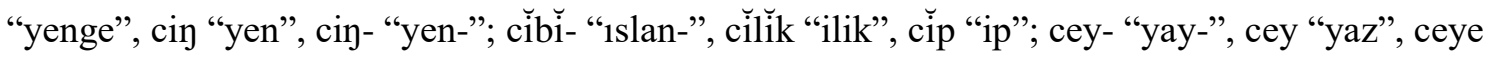
"yay", ceyev "yaya", cerin "gelecek yıl”; cürme- "elle dik-" vd.) gelmektedir. Ancak a, 1, o gibi kalın sıradan ünlülerden önce gelen (cayna- "parla-, parılda-", calpay- "büyü-, yetiş-"; cılı "sıcak", cır "türkü", cıy- "yı̆̆-", c1yır- "büz-, buruştur-", c1lbır-cılbır "parıl parıl"; comak "bilmece", cot "hayvanların açlıktan kırılması, kırım" vd.) epeyce kelime de vardır.

Görüldüğü gibi Tatar yazı dilinde ön seste y-/c- sesi karışık olarak görülmekte ve diğer Türk lehçelerinden farklılık arz etmektedir. Ahmet B. Ercilasun, Tatar yazı dilinde y->cdeğişmesinin bilhassa /i/ ünlüsünden önce cil "yel”, cir "yer" gibi kelimelerde ortaya çıktığını belirterek bu durumun diğer Kıpçak lehçelerinin Tatar Türkçesine tesiriyle açıklamaktadır (Ercilasun, 2007: 114). Ancak gerek Tatar Türkçesinin tarihî dönemleri gerekse ağızları dikkate alınırsa, Tatar Türkçesinde ön ses $y$->c- sesinin değişiminin diğer Kıpçak lehçelerinin etkisinden ziyade kendi yapısı ve şartları göz önünde tutularak değerlendirilmesi gerekliliği 
ortaya çıkmaktadır. Bu çalışmada da Tatar Türkçesinin tarihî metinleri ve ağızları incelenerek söz konusu durum hakkında bir değerlendirme yapılacaktır.

Türkçenin elimizde bulunan ilk yazılı belgelerinde /c/ sesi bulunmamaktadır. Dolayısıyla Köktürk ve Uygur dönemi eserlerinde ön seste y-/c- denkliği bulunmaz ve ön seste /y-/nin korunduğu görülür. Ön seste y-/c- meselesiyle ilgili ilk kayıt Dîvânu Lugâti't-Türk’te geçer. Kâşgarlı Mahmud, lehçelerin farklılıkları hakkında bilgi verirken o dönem Türk lehçelerinde ön seste y-/c- ile ilgili olarak "Bütün isim ve fiillerin başındaki ye'ler Oğuzca ve Kıpçakçada elif veya cim'e döner. Meselâ Türkler "yolcu”ya yelgin derler, bunlar ise elgin; Türkler "llık su"ya yıllg su.w, bunlar ise elif'le ılıg derler. Aynı şekilde Türkler "inci" ye yinçü, bunlarsa cinçü derler. Türkler devenin tüyleri için yogdu, bunlar cogdu der." diyerek yinçü ve yogdu kelimelerinin Oğuzca ve Kıpçakçada cinçü ve cogdu şeklinde söylendiğini belirtmektedir (Ercilasun-Akkoyunlu, 2014: 12). DLT'de bu iki kelimenin dışında çeşitli sayfalarda ön ses y/c- için Oğuz ve Kıpçaklarda cet- (yit-) "yetiş, ulaş-" (DLT 331), cun- (yun-) "yıkanmak" (DLT 331), Kıpçak vb.lerinde cigi (yigi) "sağlam, sık dikiş" (DLT 446) örnekleri vardır. Böylece DLT'de yet-/cet-, yigi/cigi, yinçü/cinçü, yogdu/cogdu, yun-/cun olmak üzere beş kelimede ön seste $y->c-$ değişimi görülmekte ve Kâşgarlı bu durumu bir Oğuz ve Kıpçak özelliği olarak açıklamaktadır.

Zeynep Korkmaz, Kâş̧garlı'nın DLT'de Oğuzca ve Kıpçakça için belirttiği y->-c değişiminin 11. yüzyıldan sonraki Oğuzca metinlerde bulunmadığını, tersine bu ses değişiminin Kıpçakçada olduğunu, bu yüzden de Kâşgarlı'nın y->-c değişimini Oğuzca için vermesinin bir yanlışlık olarak kabul edilebileceğini söyler (Korkmaz, 1973: 44). L. Celey de Kâşgarlı'nın belirttiği durumun kısmen kabul edilebileceğini çünkü Oğuzlarda böyle bir ses değişiminin olmadığını Kıpçak boylarının tamamında da c- kullanılmadığı belirtir (Celey, 1964: 62). Kaşgarlı'nın hem Oğuzlar hem de Kıpçaklar için belirttiği durum o dönem için geneli temsil etmeyip bir ağız özelliği olmalıdır. Zira, tarihî dönemdeki Türkçe yazılı eserlere bakıldığında ön seste y-'nin büyük oranda korunduğu görülmektedir. Gürer Gülsevin de Dîvânu Lugâti'tTürk'teki verilere dayanarak 11. yüzyılda Oğuz diyalektlerini belirlediği çalışmasında Kaşgarlının Oğuzca için kaydettiği ses özellikleri dışında aykırı örneklerin bulunmasını o dönemde birden fazla Oğuz ağzı bulunmasıyla açıklar (Gülsevin, 2016: 272-294). Dolayısıyla aynı durum Kıpçakça için de geçerli olmalıdır. Bugün Kıpçak lehçelerinde, Tatar yazı dilinde ve ağızlarında ön seste hem y- hem de c-'li örneklerin bulunması tarihî dönemlerde de farklı ağızların bulunduğu anlamına gelir.

Funda Toprak, Dîvânu Lugâti’t-Türk’te Kıpçakça kaydıyla verilen kelimelerin tarihî Kıpçak söz varlığı içindeki yerini incelediği çalışmasında Divan'da ön seste y- ile başlayan dokuz kelime göstermektedir. DLT'de bunlardan dördü (yayğuk yazğuk "kısrak memesinin ucu, yimşen "Kıpçak ülkesinde yetişen yabani bir meyvenin adı", yükünç "namaz", yal"yanmak") Kıpçak kaydıyla; dördü (yawlak "kötü, düşkün”, yen- "yen-”, yubıla- "aldat-, hile yap-", yut- "yut-") Oğuz ve Kıpçak kaydıyla; biri de (yalıuk "cariye, odalık”) Oğuz, Kıpçak ve Suvar kaydıyla gösterilmiştir (Toprak, 2003: 81-88). Dolayısıyla Kaşgarlı Mahmud'un "Bütün isim ve fiillerin başındaki ye'ler Oğuzca ve Kıpçakçada elif veya cim'e döner." ifadesine rağmen eserde Kıpçak kaydıyla verilen beş kelime c- sesi ile başlarken, yine Kıpçakça kaydı ile verdiği dokuz kelime ise $\mathrm{y}$ - ile başlamaktadır. Gülsevin, Kaşgarlı Mahmut'un eserinin başlarında "Diyalektlerin Değişiklikleri Üzerine Söz" başlı̆ğ altında verdiği bilgilerden Oğuzcaya ait olanların, muhtemelen en yaygın olan ve Selçukluları en iyi temsil eden prestij ağzı olmalıdır, der (Gülsevin, 2016: 289). Hâliyle bu durum Kıpçak lehçeleri için de düşünülmeli ve Kaşgarlı'nın eserini yazdığı dönemde Kıpçakçanın da farklı ağızlarının bulunduğu gözden uzak tutulmamalıdır.

Kâşgarlı Mahmud'un belirttiği durum bir tarafa bırakılırsa Eski ve Orta Türkçe dönemi eserlerinde ön seste y-nin korunduğu görülür. Harezm Türkçesi (Argunşah-Sağol YüksekkayaTabaklar 2010: 115) ile Memlûk-Kıpçak sahası eserlerinde ortak Türkçe kelimelerde kelime başı /y/ sesi, /y/ olarak görülür (Özyetgin, 2001: 107). Hatta Karadeniz'in kuzeyindeki Kıpçak 
(Kuman) Türklerine ait olan ve Kıpçak ağızlarından derlenerek oluşturulan (Ercilasun, 2004: 386) Codex Cumanicus'ta ve Ermeni harfli Kıpçak Türkçesi metinlerinde de Türkçe kelimelerde ön seste y- görülmektedir (Argunşah-Güner, 2015: 63-64).

Tatar Türkçesi Orta (Kazan), Batı (Mişer) ve Doğu (Sibirya) olmak üzere üç büyük ağız grubundan meydana gelir. Tatar yazı (edebî) dilinin kuralları büyük oranda Orta (Kazan) bölgesi ağızlarına dayanır. Yazı dilinin fonetik unsurları ve söz varlığı Orta ağız grubuna, morfolojik kuralları büyük oranda Batı (Mişer) ağızlarına, söz dizimi ve üslup özellikleri de ortak Türkçeye ve eski Tatar edebî diline dayanır (Zekiyev, 1998: 554; Mexmutova-Borhanova, 1969: 613; Exetov, 1984: 13). Tatar Türkçesinin yazı dili hâline gelmesi 19. yüzyılın sonları ile 20. yüzyılın başlarında gerçekleşir. Orta (Kazan) diyalektin özellikle de onun Kazan ardı ağızları edebî norm olarak kabul edilir, diğer diyalektlerin de bu ağızlara uygunlaştırılması 1905 yılındaki devrimi doğuran sosyal hareketlerin neticesi olarak ortaya çıkar. Ancak Tatar edebî dilinin standartlaşması, yaygınlaşması, halk diline yaklaştırılması, ağızlara dayandırılması, ağızlardan alınan kelimelerle zenginleştirilmesi, kurallarının belirginleştirilmesi, devlet dili durumuna gelmesi 1917 Bolşevik ihtilalinden sonra gerçekleştirilir (Celey, 1947: 10-11). Bu arada, Tatar ağızlarının birbirine yakın olduğunu ve aralarındaki farkların da çok büyük olmadığını belirtmekte fayda vardır.

Tatar halkının bir coğrafyada, merkezî bir devlet bünyesinde yaşaması İdil boyu Bulgar Devleti zamanından başlayıp Altın Orda ve Kazan Hanlığı dönemlerinden devam edip gelmektedir. Haliyle İdil Bulgar Devletinden kalan mezar taşları Tatar Türkçesinin ilk edebî ürünleri olarak değerlendirilmektedir. İdil Bulgarlarından kalan mezar taşlarında ön seste y-/ckullanımını bir arada görmek mümkündür:

Axirata bațuwi hicratran alț cü̈r toxur wanım cal şa'bān ayxi bèlinci küwen eti (Tekin, 1988: 56); wafati balțwi tārīxa ciyeti cüür ciyerminşi cal muharram ayxi belinci küwen eti (Tekin, 1988: 74); tārīxa ciyeti cü̈̈r cīrem ciyeti cal eti (Tekin, 1988: 120) gibi örneklerde ciyeti "yedi", cür "yüz", cīrem "yirmi", cal "y1l” kelimelerinde ön seste c- sesi bulunurken Bılgari Musa ogılı Receb ziyareti turur. Axir vefatı birilmis tarihte yiti yüz ikirmi tokuzında irdi; Rebiülahir ayının sekizinde tarih yiti yüz otuz törtte irdi (1338 tarihli); Yigirmi iki yaşında vefat boldu hicretde yiti yüz onbirdi (1311 tarihli); Yigirmi iki yaşına vefatı boldu... yılı it cırtan yiti yüz otuz yitide (Celey, 1954: 63) gibi örneklerde ise yidi, yüz, yigirmi, yıl, yaş gibi kelimelerde ön seste y- bulunmaktadır. L. Celey, Bulgar kabir taşlarında ön seste y-/c- sesinin bir arada bulunmasını bir ağız özelliği olarak değerlendirir ve bugün de Tatar Türkçesi ağızlarında görülen bu durumun Bulgar dönemine kadar uzandığını belirtir (Celey, 1954: 64).

Eski Tatar edebî diline ait metinlerde de ön seste y-nin korunduğu görülmektedir. Kazan Hanlığ devrinde ve daha öncesinde yazılan Tuhfe-i Merdan, Nur-1 Sudur gibi eserlerde ön seste sıklıkla c- yerine y- sesinin yazıldığı tespit edilmiştir. Meselâ cir yerine yir "yer", cil yerine yil "yel” gibi (Xakov, 2003: 84). Hatta ön seste y- kullanımı 19., 20. yüzy1la kadar devam ederek Kayyum Nasıyri, Abdullah Tukay'ın eserlerine de yansır. Celey, Bulgar kabir taşlarında ön seste kullanılan c- sesinin 14. yüzyıldan sonra y- olarak görülmesini de Batı (Mişer) ağızlarının yazı dilini etkilemesi ve daha baskın hâle geçmesiyle açıklar (Celey, 1947: 4). 14-15. yüzyıldan 20. yüzyıl başlarına kadar ön seste aktif olarak y- sesi görülürken 1917'deki Bolşevik ihtilalinden sonra y- ile birlikte c- sesi de aktif hale getirilir.

Ön seste y-/c- kullanımı Tatar diyalektolojisinde ağızların sınıflandırılmasında esas alınan ölçütlerden biridir. Buna göre Orta (Kazan) ağızlarında yaygın olarak ön seste c- sesi kullanılırken Batı (Mişer) ve Doğu (Sibirya) grubu ağızlarında ise ön seste y- sesinin kullanımı hâkimdir (Yusupov, 2003: 32). Bu sebeple Orta (Kazan) ağızları c'leştirici, diğer iki ağız ise y'leştirici ağız olarak kabul edilmektedir (Celey, 1947: 14). Kısmen edebî dilin ağızlara tesiri ve ağızların birbirine tesiri neticesinde ağızlar arasında y-/c- geçişleri görülse de büyük oranda ön seste Orta ağız bölgesi c- sesini, Batı ve Doğu grubu ağızları ise y- sesini barındırır. 


\section{Tatar Ağızlarında Ön Seste y-/c- Sesinin Görünümü}

Tatar Türkçesinin ağızları kendi içinde Kazan (Orta), Mişer (Batı), Sibir (Doğu) olmak üzere üç büyük gruptan oluşmaktadır. Orta (Kazan) diyalektin konuşucuları büyük çoğunluğu Tataristan, Başkurdistan, Mari, Udmurt ve Çuvaş özerk cumhuriyetleriyle Rusya Federasyonuna bağlı Kirov, Ryazan, Perm, Sverdlovsk, Çilebi gibi bölgelerde, Batı (Mişer) diyalektinin konuşucuları Gorkiy, Ulyanovsk, Penza, Saratov, Kuybışev, Volgograd, Orenburg bölgeleriyle Tataristan ve Başkurdistan cumhuriyetlerinin çeşitli yerlerinde bulunmaktadırlar. Doğu diyalektinin konuşucuları da Batı Sibirya'da Tümen, Omsk ve Novosibirsk gibi yerlerde yaşamaktadırlar (Alkaya, 2014: 44).

Üç büyük grubun da kendi içerisinde alt ağız bölgeleri bulunmaktadır. Buna göre Tatar Türkçesinin üç ağız grubunun kendi içerisindeki bölümlendirilmesini de şu şekilde göstermek mümkündür:

\section{Orta (Kazan) Diyalekt:}

1. Kazan Ardı Ağızları (1.1. Döbyaz Ağz1, 1.2. Mamadış Ağz1, 1.3. Baltaç Ağz1, 1.4. Layış Ağz1), 2. Berengi Ağz1, 3. Tav Yagı Ağıları (3.1. Nurlat Ağz1, 3.2. Kama Tamag1 Ağz1, 3.3. Tarxan Ağzı), 4. Kreşin Ağızları Grubu (4.1. Kazan Ardı Kreşinleri Ağzı, 4.2. Tüben Kama Kreşinleri Ağz1, 4.3. Nagaybek Ağz1), 5. Nokrat Ağz1, 6. Kasım Ağz1, 7. Bastan Ağz1, 8. Perm Ağzı, 9. Minzele Ağzı, 10. Böri Ağzı, 11. Orenburg Bölgesi Ağızları (11. 1. Bogrıslan Ağızlar1, 11.2. Kargalı Ağz1), 12. Kamışlı Ağz1, 13. Krasnoufim Ağz1, 14. Zlatoust Ağz1, 15. İçkin Ağz1, 16. Turbaslı Ağz1, 17. Tipikey Ağz1, 18. Uçalı Ağz1, 19. Safakül Ağz1, 20. Esterhan Ağz1, 21. Tatar-Karakalpaklar Ağzı.

\section{Batı (Mişer) Diyalekti}

1. Temnikov Ağzı, 2. Lembre Ağz1, 3. Kuznetsk Ağz1, 4. Xvalın Ağz1, 5. Karsun Ağz1, 6. Mordva-Karatay Ağzı, 7. Melekes Ağz1, 8. Çistay Kreşinleri Ağzı, 9. Tav Yagı (Podbereze) Kreşinleri AğZ1, 10. Sterlitamak A ̆ğ1, 11. Şarlık Ağzı, 12. Kostroma AğZ1, 13. Volgograd Ağzı, 14. Sergaç Ağzı, 15. Çüpreli Ağzı, 16. Sırkıdı Ağzı, 17. Tatarşçino (Kürşe) Köyü Ağzı, 18. Çistay Ağzı, 19. Baykıbaş Ağzı.

\section{Doğu (Sibirya) Diyalekti}

1. Tobol-İrtiş Ağızları (1. 1. Tümen Ağzı, 1. 2. Tobol Ağzı, 1. 3. Saz Yag1 Ağz1, 1. 4. Tara Ağzı, 1. 5. Tevriz Ağzı), 2. Baraba Ağzı, 3. Tom Ağızları (3.1. Yevişte-Çat Ağzı, 3.2. Kalmak Ağzi)*.

Tatar Türkçesi ağızlarında ön ses y-'nin görünümü farklılık arz etmektedir. Mişer ve Sibirya grubu ağızlarında ön seste y- görülürken Orta (Kazan) grup ağızlarında ön seste çoğunlukla c- görülmektedir. Sibirya ve Mişer grubu ağızları bu sebeple y'leştirici ağızlar, Orta (Kazan) grup ağızlarda c'leştirici ağızlar (Exetov, 1984: 31) olarak kabul edilmektedir. Bu ağızlar içinde ön ses y-‘ yi en güçlü olarak koruyan ağızlar Sibirya grubu ağızlarıdır. Bu ağızların coğrafi olarak Orta grup ağızlarından uzak olması ve daha izole bir durumda bulunması sebebiyle ön seste y- güçlü bir şekilde korunmuştur. Edebî dilin etkisi ve daha çok bireysel kullanıma bağlı olarak az da olsa ön seste y->c- dönüşümü de görülür: cil "yel, rüzgâr", cir "yer", crrla- "şarkı söyle-", ceye "yay" (Alkaya, 2008: 73).

\footnotetext{
* Tatar Türkçesi ağızlarının sınıflandırılması için bk. F. S. Bayazitova vd., Tatar Xalık Söyleşlerº I, II, Kazan 2008.
} 
Mişer grubu Tatar ağızları da ön seste y-'yi büyük ölçüde koruyan ve bu sebeple de y'leştirici ağızlar olarak kabul edilen ağızlardır (Bayazitova, 2003: 240). Ancak Mişer ağızlarında da daha çok genç neslin konuşmasında ön seste $y$->c- değişmesine rastlanmaktadır. $\mathrm{Bu}$ durum edebî dilin etkisine bağlı olduğu gibi Orta grup ağız konuşurlarılyla bir arada yaşamaya bağlı olarak da ortaya çıkmaktadır: cıl "yıll", citmiş "yetmis, 70", cey "yaz", cir "yer",

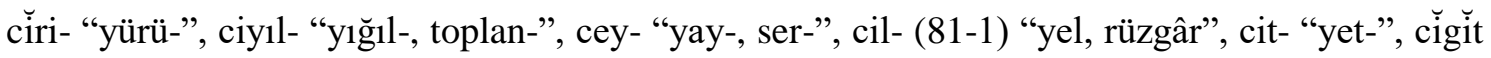
"yiğit, genç", cigirmi “yirmi”, c1lan "y1lan”, cag- "yak-", ceye "yay”, c1rla- "sark1 söyle-”, cort "yurt, ev" (Alkaya, 2014: 48).

Orta (Kazan) grup ağızlarında diğer iki ağız grubundan farklı olarak ön seste y- yerine c- sesi kullanılmaktadır. Orta grup ağızları bu özelliğinden dolayı c'leştirici ağızlar olarak nitelendirilmektedir. Ancak, Mişer gruplarıyla bir arada yaşayanların ağızlarında ve kısmen de yazı dilinin etkisiyle ön seste y- kullanımına da rastlanmaktadır. İdil boyu Tatarları tarihte Türk olarak adlandırılan çeşitli boyların ve az sayılı bazı halkların bir araya gelmesiyle şekillenmiştir. İdil Tatarlarının yapısında ve oluşumunda eski Bulgar, Çuvaş, Kıpçak, Hazar, Başkurt boylarının çeşitli kabileleri bulunur. Bu tarihî olgu, Tatar Türkçesinin diyalektal çeşitliliğinde de kendisini göstermektedir (Celey, 1947: 9).

Tatar Türkçesinin üç büyük ağız grubunun genel karakteristiği yukarıda belirtildiği gibi olmasına rağmen ağız grupları içerisinde ön seste y-'nin korunması veya c-/dc-/dz-/d-/z-/j- gibi seslere dönüşmesi de görülebilmektedir. Ön seste y-'nin durumu bakımından Tatar Türkçesi ağızlarında aşağıdaki durum söz konusudur:

\section{1. Ön Seste /y-/nin Korunması}

Yukarıda da belirtildiği gibi Sibirya ve Mişer grubu ağızları y'leştirici ağızlar olarak kabul edildikleri için ön seste y- büyük ölçüde korunmaktadır.

Sibirya ağızları bu yönüyle ön seste y-'yi sistemli olarak koruyan ağızlardır: Kelime başında bulunan bütün /y/ler aslidir: Tev. yorço (<yurç. OTG, 260) "kayın birader", Tüm. yılı $(<y$ ylı̆̆. ETG, 310) "sıcak", Tüm. yĭgit “yiğit, genç”, Tom. yözök "yüzük”, Tev. yul "yol” (STT, 92), Saz Y. yintsĭ “inci” (STT, 504), Yev.-Çat. yıraq "uzak” (STT, 575), Tob. yĭnke “yenge”. (TXS II, 279), Tar. yit- “yet-” (TXS II, 342), Bar. yös “yüz” (TXS II, 397), Kal. yörï“yürü-”. (TXS II, 445).

Mişer ağızları da genel karakteristiği bakımından ön seste y-'yi koruyan ağızlardan oluşur. 19 ağızdan ibaret olan Mişer grubunda Tatarşçino, Tav Yagı (Podbereze) ve MordvaKaratay ağızları dışında kalan 16 ağızda ön seste y- kullanımı görülür. Bu ağızlarda çeşitli sebeplere bağlı olarak ön seste y- kullanımının yanı sıra bu sesin kısmi olarak /c-/, /dc/, /dz-/, /z/, /j-/ gibi seslere dönüştüğü de görülmektedir. Bu seslerle ilgili durumlar ilgili başl1klar altında gösterilecektir. y- sesinin korunduğu örnekler: Ser. yıl "yıl”, (MTT, 64), Çüp. yugarı "yukarı" (MTT, 64), Kuz. yaz- "yaz-" (MTT, 64), Xva. yidi "yedi, 7” (MTT, 64), Kos. yumurka "yumurta" (MTT, 653), Sır. yırt "ev" (MTT, 479), Çis. yırtıl- (MTT, 444), Bay. yasa- "yap-" (MTT, 461), Lem. yakş1 “iyi”" (TXS II, 30), Kar. yïri- "yürü-” (TXS II, 74), Mel. yị “ip" (TXS II, 99), Şar. yir “yer” (TXS II, 156), Vol. yil “yel” (TXS II, 172), Bay. yasa- "yap-” (MTT, 461).

Orta (Kazan) Grubu ağızları genel karakteristiği bakımından ön ses y-‘nin c- olduğu ağızlardır. Bu sebeple Tatar diyalektolojisinde c'leştirici ağızlar olarak bilinir. Ancak, kendi içerisinde 21 ağızdan ibaret olan bu ağız grubunun kimi ağızlarında ön seste c- ile birlikte y- de görülmektedir. Bu durum daha çok Mişer ağız grubu konuşurlarıyla bir arada yaşamaktan ve edebî dilin etkisiyle ortaya çıkmaktadır. Diğer Orta (Kazan) grubu ağızlarından farklı olarak 
Nokrat, Kamışlı, Zlatoust, İçkin, Tipikey, Uçalı ve Safakül ağızlarında ön seste güçlü bir yeğilimi görülmektedir. Bu ağız konuşurlarının daha çok Başkurdistan'a ve Sibirya Tatarlarına yakın bölgelerde bulunması (Yusupov, 2003: 133), Başkurt veya Mişerlerle bir arada yaşamaları y- sesinin ön plana çıkmasına sebep olmuştur: Nok. yırla- "şarkı söyle-" (US, 132), Kam. yĭmiş “yemiş" (ETD, 86), Zla. yïr "yer” (TXS I, 319), İçk. yılı "sıcak” (US, 244), Tip. yiy- "yığ-, topla-" (TXS I, 360), Uça. yil "yel” (TXS I, 374), Saf. yiti “yedi, 7” (ST, 77).

Ön seste y- sesini koruyan ağızlarda güçlü y'leşme eğiliminden dolayı kimi alıntı kelimelerdeki /c/ sesleri /y/ye dönüşmektedir: Bör. yawap (<Ar. cevāb) "cevap". (TXS I, 244), Kam. yemeğet (<Ar. cemāat)"cemaat" (TXS I, 293), Bay. yafa ( $<$ Ar. cefā) (32-15) "cefa" (MTT, 155), Ser. yıma (<Ar. cum'a) (2-43) "cuma" (MTT, 155), Çüp. yan (<Far. cān) (16-3) "can" (MTT, 155), Çis. yanwar (<cān-āver) (18-1) "canavar", Zla. meryen (<Ar. mercān) "mercan" (TXS I, 319).

\section{2. Ön seste c- kullanılan (y->c-) ağızlar}

Orta (Kazan) grubu ağızları ön seste y->c- değişiminin güçlü olarak görüldüğü ağızlardır. Bu yönüyle ayırıcı bir özelliği de olan bu ağızlar Tatar dil biliminde c'leștirici ağızlar olarak adlandırılmaktadır. Bu ağızlar içinde Layış, Berengi, Nurlat, Kama Tamagı, Tüben Kama Kreşinleri, Nagaybek, Tatar Karakalpaklar ağızları ön seste c- nin kullanıldığı ağızlardır. Mamadış, Tarhan, Kazan Ardı Kreşinleri, Kasım, Perm, Minzele, Böri, Turbaslı ağızlarında da ön seste yaygın ve güçlü bir c- görünümü vardır:

Lay. cılan "yılan”. (TXS I, 43), Nur. canğır "yağmur" (TXS I, 58), Kam. Tam. ceşĭl “yeşil” (TXS I, 70), Mam. cozoroq “yumruk” (TXS I, 30), Tarx. cirrek “yürek” (TXS I, 80), Tüb. Kam. Krş. cana "yeni”" (MTD 1974, 196), Nag. caz "bahar" (Yosipov 2015, 15), Kas. c1l "yıl" (ETD, 88), Per. canış "yanlış" (TXS I, 188), Min. cök "yük" (ETD, 45), Bör. cul "yol” (TXS I, 244), Tur. cir “türkü” (TXS I, 350).

Mişer grubu ağızlarından Sterlitamak ağzında ön seste y-/c- kullanımı bakımından karışık olsa da c- kullanımı bakımından biraz daha öne çıkmaktadır: cıyıl- "yığıl-, toplan-", cir "yer”, cigirmi “yirmi, 20”, c1lan "yılan” (MTT, 444).

Ön seste c- sesini barındıran ağızlarda güçlü c'leşme eğiliminden dolayı kimi alıntı kelimelerdeki /y/ sesleri /c/ye dönüşmektedir: Lay. çimce ( $<$ Rus. semya) "aile" (TXS I, 43), Ber. dönca ( $<$ Ar. dunyā) "dünya" (TXS I, 50), Kaz. Ard. Krş. pamilce ( $<$ Rus. familiya) "soyadı", (TXS I, 95), Bör. werince (<Rus. varenye) "reçel" (TXS I, 244), Tur. prawlince $(<$ Rus. pravleniye) "idare, yönetim" (TXS I, 350), Mor.-Kar. piçince ( $<$ Rus. peçenye) "bisküvi”. (TXS II, 79), Ste. fitca (<Ar. fidye) “ölen kişinin hayrına verilen sadaka” (TXS II, 131).

\section{3. Ön seste y- ve c-'nin birlikte görüldüğü (y- c-) ağızlar}

Ön seste y- ve c-'nin güçlü olarak görüldüğü ağızları yukarıda belirtmiştik. Yukarıda belirtilen ağızlar y- ve c-'yi korumuş olsalar da çeşitli sebeplerle bu seslerin karışık kullanımına da rastlanmaktadır. Ös seste y-'nin güçlü olduğu ağızlarda c-; c-'nin güçlü olduğu ağızlarda da $\mathrm{y}$ - kullanımı görülebilmektedir. Bu ağız konuşurlarının bir arada yaşamaları, bilhassa genç neslin konuşmasında yazı dilinin etkisi, kimi ağızların Başkurt ve Mişer ağızlarıyla iç içe olması (Exetov 1984: 53) bu karışık kullanımın ortaya çıkmasına sebep olmaktadır. Sibirya (Doğu) grubu ağızları ön seste y-'nin kullanılması bakımından daha belirgindir. y- c- paralel kullanımı daha çok Orta (Kazan) ve Batı (Mişer) ağızları arasında görülmektedir. F. Yusupov, coğrafi durumu da göz önünde bulundurarak meselâ Krasnoufim ağzında c- ve y- seslerinin paralel kullanımının Tatar Türkçesinin c'leştirici Orta (Kazan), y’leştirici Sibir Tatarları ağızları 
ve y'leştirici Başkurt Türkçesinin birleştiği alanda oluşmasından kaynaklandığını söyler (Yusupov, 2003: 33). Bu durumun paralel kullanımın görüldüğü diğer ağızlar için de geçerli olduğu söylenebilir.

Orta (Kazan) grubu ağızlarından Mamadış, Baltaç, Berengi, Tarxan (Bua rayonunun bazı köyleri), Kazan Ardı Kreşinleri, Nokrat (Glazov bölgesi), Perm, Minzele (Belebey bölgesi), Bogrıslan, Kargalı, Kamışlı, Krasnoufim, İçkin, Turbaslı ağızlarında y- c- kullanımı kısmi olarak bulunmaktadır. Baltaç, Bogrıslan, Kargalı ve Esterxan ağızlarında ise y- c- paralel kullanımı daha yaygındır: Mam. yawım $\sim$ cawım "yağış" (TXS I, 30), Bal. yastıq $\sim$ castıq "yastık" (TXS I, 38), Ber. yakın cakın "yakın" (ETD, 58), Tarx. yuq cuq “yok" (TXS I, 80), Kaz. Ard. Krş. yurğan curğan "yorgan" (TXS I, 95), Nok. cit- yit- "yet-" (US, 132), Per. yabu cabu "masa örtüsü" (TXS I, 188), Min. yul cul "yol” (TXS I, 219), Bog. yögör cögîr- "koş-" (TXS I, 258), Karg. yon cön “yün” (TXS I, 274), Kam. yır cır "türkü" (TXS I, 293), Kra. y1lk1 c1lk1 "y1lk1, at” (US, 32), Tur. yeşil ceşil "yeşil” (TXS I, 350), İçk. yeyew ceyew "yaya". (US, 244), Est. yiber- ciber- "gönder-" (TXS I, 396).

Mişer grubu ağızları da ön seste y-'nin ağırlıklı ve güçlü olarak kullanıldığı ağızlardır. Yine de farklı oranlarda Lembre, Kuznetsk, Xvalın, Karsun, Çistay Kreşinleri, Sterlitamak, Şarlık, Kostroma ve Sırkıdı gibi kimi Mişer grubu ağızlarında ve bu ağızların kendi içerisindeki kimi yerleşim birimlerinde y- c- paralel kullanımına rastlanmaktadır: Lem. yïgirmi $\sim$ cigirmi (TXS II, 30), Kuz. yiy- ciy- (MTT, 538-539), Xva. yeyew ceyew "yaya" (TXS II, 55), Kar.

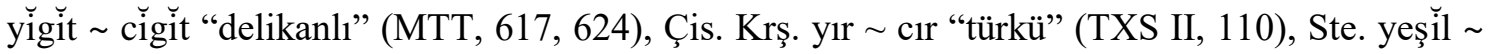
ceşil "yeşil" (TXS II, 131), Şar. yeyew ceyew "yaya". (TXS II, 156), Kos. yırla- cırla"türkü söyle-" (MTT, 655), Sir. yinge cinge "yenge” (TXS II, 208).

Orta (Kazan) grup, Batı (Mişer) grubu ve daha seyrek olarak Doğu (Sibirya) grubu ağızlarında y-'nin c-'ye değişmesi dışında, y- sesinin c-'ye değişmesinden sonra /c/ sesi üzerinden dc-, d'c'-, dz-, dz'-, d'z'-, tç- gibi birleşik sesler ve bu seslerin tekleşmesiyle de c', ç, d, $\mathrm{d}^{\prime}, \mathrm{z}, \mathrm{z}^{\prime}, \mathrm{j}$ - gibi normal veya palatal sesler ortaya çıkar.

y->c- üzerinden ortaya çıkan dc-/ d'c'-/ dz-/ dz'-/ d'z'-/ tç- gibi birleşik sesler daha çok Mişer grubu ağızlarında daha az oranda ise Orta grup ağızlarında görülmektedir. Tatar Türkçesi ağızlarında birleşik ve palatal seslerin meydana gelmesi daha çok komşu halkların tesiriyle ve bir arada yaşamaktan kaynaklanmaktadır. L. Ş. Arslanov'a göre Mişer Tatar ağızlarındaki palatalleşmiş ünsüzlerin varlığı Mordvincenin etkisiyle ortaya çıkmıştır (Arslanov, 1991: 15). L. T. Maxmutova da palatalleşmiş ünsüzlerin Fin-Ugor dillerinden Mordvince (d', t', z', s', l', n', r', ts'), Udmurtça (d', t', z', s', l', n', ç') ve Komicede (d', t', z', s', l', n', ç, dz") görüldüğünü belirterek Mişer ağızlarındaki palatal unsurların, komşuluk ilişkileri ve aynı coğrafyada yaşamadan dolayı, Mordvincenin etkisiyle oluştuğunu söylemektedir (Maxmutova, 1978: 56-57). Osman Nedim Tuna da Türkçenin tarihî dönemlerinde ve yine günümüzde bazı ağızlarında (Altay ve Ural Türk ağızları) görülen palatalleşme olayını komşu dillerin (Slav, Ural) tesiriyle açıklamaktadır (Tuna, 1960: 215). Exetov, Tatar Dialektologiyeš bulunduğu Sergaç, Çüpreli, Lembre, Temnikov gibi Mişer grubu ağızlarının dil özelliklerini ele alırken Mişerlerin bu bölgelerde Rus, Mordvin, Çuvaş gibi unsurlarla karışık ve bir arada yaşadıklarını belirtir (Exetov, 1984:103-115).

\section{4. Ön seste $y$->dc- değişmesi}

Ön seste y->dc- değişimi bilhassa Mişer grubu ağızlarına has olan bir değişmedir. Mişer grubu ağızlarından en çok Mordva-Karatay, Çistay Kreşinleri, Tav Yagı Kreşinleri ve Çistay ağızlarında görülen bu sese kısmen Sergaç, Temnikov, Lembre, Xvalın, Volgograd, Kuznetsk, Karsun, Şarlık, Çüpreli ve Baykıbaş ağızlarında da rastlanmaktadır (Alkaya 2014: 76). Ser. 
dcey- "yay-, ser-" (MTT, 76), Çüp. dcinge "yenge” (MTT, 76), Çis. dcidí “yedi, 7” (MTT, 76), Bay. dcit- (32-9) "yet-" (MTT, 76), Lem. 'ciy- "yı̆̆-, topla-" (MTT, 76), Xva. dcibek (<yipek. KTS, 324) "ipek" (MTT, 76), Mor.-Kar. dcanır (113-17) "yağmur (MTT, 76), Kar. dcïğ̈rmi "yirmi, 20" (MTT, 76), Çis. Krş. dcar- (138-1) "yar-" (MTT, 76), Tav. Y. Krş. dcuk (143-34) "yok" (MTT, 76), Kuz. dcik- "atı arabaya koş-" (MTT, 527), Şar. dcir "yer, toprak" (MTT, 582), Tem. dcitmiş “yetmiş, 70" (MTT, 508), Vol. dcil “yel” (TXS II, 177).

Mişer ağızlarına has bir ses olan dc- bilhassa Mişer ağız konuşurlarıyla bir arada yaşayan veya Mişerlere sınırdaş olan (Bayazitova vd., 2008a: 156, 168) Döbyaz, Nurlat, Kazan Ardı Kreşinleri, Tüben Kama Kreşinleri, Kasım ve Bastan ağızlarında görülmektedir. y- ve c'nin dışında görülen dc- gibi seslerin konuşulduğu ağızlarda etnik bakımdan karışıklık veya diğer dillerin etkisi de görülür. Kazan Ardı Kreşinleri, Tüben Kama Kreşinlerinin ağızlarında Rus, Çuvaş, Mari, Mordvin, Udmurt gibi halkların dil özellikleri vardır. Aynı zamanda Hristiyanlaşan bu Tatarlar adı geçen halklarla bir arada yaşamakta ve bu durum da dil özelliklerini etkilemektedir. Ayrıca Mari, Udmurt, Çuvaş gibi unsurların bir kısmının zamanla Tatarlaşması veya Tatar gruplarıyla karışması farklı dil özelliklerinin ortaya çıkmasına sebep olmuştur (Bayazitova vd., 2008a: 87, 111).

dc- sesi Orta (Kazan) grubu ağızlarından Döbyaz, Kasım ve Bastan ağızlarında yaygın, Nurlat, Kazan Ardı Kreşinleri ve Tüben Kama Kreşinleri ağzında da dağınık olarak

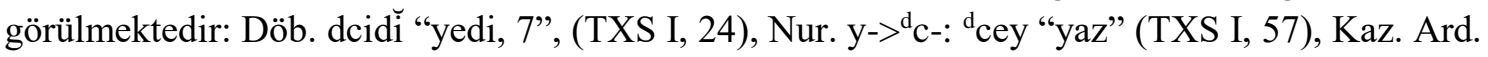
Krş. dcıy- "yı̆g-" (GTK, 199), Tüb. Kam. Krş. dcuk "yok" (GTK, 226), Kas. dcul "yol” (TXS I, 160), Bas. dcımşaq “yumuşak" (TXS I, 170).

\section{5. Ön seste y->d'c'- değiş̧mesi}

Ön seste y->d'c'- değişimi Mişer ağızlarından Mordva-Karatay ağzında görülür. y- sesi bu ağızda ve yukarıda da görüldüğü gibi bir çok ağızla patlamalı dc- sesine dönüşür. Güçlü patlamalı dc- sesi Mordva-Karatay ağzında incelerek palatal d'c'- şeklini alır (Bayazitova vd. 2008a: 78). Palatal sesler bilhassa Mişer ağızlarında görülür. Mişer Tatar ağızlarında "d, l, n, r, s, t, v, z" ünsüzlerinin ayrıca yumuşamış (palatal) şekilleri de (d', l', n', r', s', t', v', z') kullanılmaktadır (Alkaya, 2014: 68).

\section{6. Ön seste y->dz- değișmesi}

Mişer grubu ağızlarında ve Orta grubun Kazan Ardı Kreşinleri ağzında görülen bir ses değişimidir. dz- sesi Mişer ağızlarından başta Kürşi (Tatarşçino) köyü ağzı olmak üzere Sergaç, Çistay, Baykıbaş, Meleks, Şarlık ve Çüpreli ağızlarında görülür.

Kür. dzandır- "yak-, yandır-" (MTT, 77), Ser. dzidi "yedi, 7” (MTT, 77), Çis. dzir "yer" (ETD, 101), Bay. dzıyıl- "yığıl-, toplan-" (MTT, 77), Mel. dzil "yel” (TXS II, 99), Şar. dzeyew "yaya” (TXS II, 156), Çüp. dzıyılış "toplantı, toplanma” (TXS II, 198).

dz- Orta grubun Kazan Ardı Kreşinleri ağzında da görülmekdedir: Kaz. Ard. Krş. dzawlıq “başörtüsü”, dzidi “yedi, 7”, dzey “yaz”, dzuq “yok”, dzuğarı "yukarı". (TXS I, 88), dzan"yan-" (GTK, 203).

\section{7. Ön seste $y->d ' z '$ - değişmesi}

Mişer grubu ağızlarından Çistay ağzında görülen bir ses değişimidir. dz- sesinin yumuşayarak palatalleşmesi sonucu meydana gelir: d'z'ey "yaz”, d'z'aylı "uygun”. (TXS II, 226). 


\section{8. Ön seste y->dz' - değișmesi}

Mişer grubu ağızlarından Çistay ve Baykıbaş ağızlarında çok seyrek görülen bir ses değişmesidir. $y->d z-$ değişmesinin ardından /z/nin palatalleşmesiyle ortaya çıkmıştır: Çis. dz'ir “yer" (MTT, 448), Bay. dz'ínge "yenge" (MTT, 476).

\section{9. Ön seste $y->z^{\prime}$ - değişmesi}

Mişer grubu ağızlarından Çistay ağzında çok seyrek görülen bir ses değişimidir. Komşu ağızların ve edebî dilin etkisiyle palatal d'z'- çift ünsüzü kullanım aktifliğini yitirmekte ve d'z'sesi z'- olarak da görülmektedir (Bayazitova vd. 2008b: 226). Böylece y->z'- değişimi ortaya çıkmaktadır:

Çis. z"aylı "uygun”, z'iyılış "toplanma, toplantı". (TXS II, 226).

\section{0. Ön seste y->tç- değișmesi}

Orta (Kazan) grup ağızlarından Kasım ağzında bilhassa yaşlıların konuşma dilinde görülen bir ses olayıdır. Ön seste görülen tç- sesi daha çok Mişer ağızlarında görülen bir sestir ve ç- sesinden (ç->tç-) dönüşür: çık->tçık-, çakır-> ç̧akır, Çuvaş>tçuvaş, uç>otç gibi. Mişer ağızlarında seyrek olarak alıntı kelimelerde /ts/ ve /c/ seslerinden de /tç/ye dönüşmektedir: çitça (<Rus. sitsev) "basma kumaş", metçit (<Ar. mescid) "mescit" (Alkaya, 2014: 93). Kasım ağzında görülen bu ses Mișer ağızlarının etkisiyle meydana gelmiş olmalıdır. Zira, orta kuşak konuşurları kendilerinin Mișer ağzıyla konuştuklarını ifade etmektedirler (Bayazitova vd., 2008a: 156).

Kas. tço'la- (ed. yokla-) "uyu-", tçıla- (ed. yıla-) "ağla-", tçiralma "patates", tçir "yer", tçıvat- (ed. yuvat-) "teskin et-, teselli et-", tçîri' "yürek", tçat- "yat-", tçeyew "yaya". (TXS I, 161).

\section{1. Ön seste $y$->ç- değişmesi}

Ön sesteki y->ç- değişmesi Sibirya (doğu) grubu ağızları ile Orta (Kazan) grup ağızlarından Kasım ve Temnikov ağızlarında seyrek olarak görülen bir ses olayıdır. Ön seste yyerine ç- kullanımı Tuva, Hakas, Şor gibi Kuzeydoğu Türk lehçelerinde görülür (Serebrennikov-Gadjieva 1979: 56). Kelime başı $\mathrm{y}>c ̧$ değişimi Tuva Türkçesinde kurallıyken, Hakas Türkçesinde de yaygın olarak görülmektedir: Tuv. yedi $>$ çedi, yok $>$ çok, yazuk $>$ çazıg "yanlış, hata", yay>çay "yaz" (Arıkoğlu 2007b: 1162) ; Hak. yurt>çurt, yıll>çıl, yı $\breve{g}->c ̧ ı$ (Arıkoğlu, 2007a: 1093). Bu ses Kasım ağzında Mişer ağızlarında da görülen ve bir üst maddede görülen tç- sesindeki /t/nin zayıflayıp düşmesiyle ( $\mathrm{y}->$ tç->ç-) ortaya çıkmış olmalıdır: çıla- (ed. yıla-) "ağla-", çıbat- (ed. yuat-) "teselli et-", çörĭ- (ed. yörĭ-) "yürü-", çat- "yat-", çiralma (<yer alma) "patates" (ETD, 88). Penza vilayetinin Kamenka rayonuna bağlı Kikın ve Muçalı ağızlarında da ön seste görülmektedir: çıy- "yı̆̆-, topla-" (ETD, 115), çılı "sıcak" (ETD, 115)

Ön seste ç- ağzı Sibirya ağızlarından Tümen, Baraba, Yevişte-Çat ve Kalmak ağızlarında seyrek olarak görülmektedir. Bu ağızlardaki $\mathrm{y}->c ̧-$ değişimi de $\mathrm{y}$->c->ç- şeklinde olmuştur. Zira, Sibirya Tatar ağızlarında tonsuzlaşma genel bir özelliktir. Hatta alıntı kelimelerdeki /c/ler de /ç/ye dönüşmektedir: höçüm ( $<$ Ar. hucūm) "hücum", çefa $(<$ Ar. cefā) "cefa", çan $(<$ Far. cān) "can, sevgili" gibi. Nitekim aşağıdaki ağızlarda /ç-/li olarak görülen örneklerin büyük çoğunluğu Tatar edebî dilinde /c-/li olarak görülmektedir (cit-, cil, c1y-, ciber-. 
bk. TTS). Dolayısıyla c- sesi Sibirya Tatar ağızları için, y- ile ç- arasında bir geçiş sesidir (Alkaya 2008: 74-75).

Tüm. çit- "yet-, ulaş-" (STT, 179), Tüm. çil "yel” (STT, 179), Tüm. çıy- "yı̆̆-, topla-" (STT, 179), Tüm. çiber- (<yiber-) "gönder-" (STT, 179), Bar. çeyin (<yay-1n) "yazın, yaz vakti”" (YST, 42), Bar. çır “türkü” (YST, 42), Yev-Çat. killçör- (<kill-ip yör-) "gel-” (DST, 234), Kal. çat- "yat-".

\section{2. Ön seste $y->c^{\prime}-$ değişmesi}

Orta (Kazan) grubun Zlatoust ve İçkin ağzında c-'nin palatalleşmesi sonucu yer yer ortaya çıkmış bir sestir. Zlatoust ağzının Belokatay rayonunun Yugarı Bilenke ağzı ile İçkin ağzının Kurgan bölgesindeki Tagıl ve Tarsuk köyleri ağızlarında görülmektedir (Bayazitova vd., 2008a: 319, 337): Zla. y->c'-: c'eyew "yaya”, c'1y- "yı̆̆g-, topla-", ' "yedi, 7”. (TXS I, 319), İçk. c'it- "yet-", c'ilan "yllan”, c'uq "yok”. (TXS I, 337).

\section{3. Ön seste $y$->d- değişmesi}

Orta (Kazan) grubun Kazan Ardı Kreşinleri ve Minzele ağızları ile Mişer grubu ağızlarından Mordva-Karatay ağzında seyrek olarak rastlanır. İlgili ağızlarda ağızda da y- sesönce dc- ve dz- seslerine dönüşür, ardından dc-'deki /c/ sesinin ve dz-'deki /z/ sesinin düşmesiyle d- sesi (y->dc-/dz->d-) oluşur (Yusupov, 2003: 245; Bayazitova vd., 2008a: 88, 219):

Kaz. Ard. Krş. duq “yok”, duğarı "yukarı", daqşı "iyi”. (TXS I, 88), Min. difek (ed. yifek) “ipek”. (TXS I, 219), Mor-Kar. dırak “uzak”, dawlık “başörtüsü” (TXS II, 79).

\section{4. Ön seste y->d'- değişmesi}

Mişer ağızlarına özgü olan palatal d' sesi Mişer grubu ağızlarından Mordva-Karatay ve Çistay ağzı ile Orta (Kazan) grup ağızlarından Döbyaz ve İçkin ağızlarında görülmektedir.

Çistay ve Mordva-Karatay ağzında ön seste y- ünsüzünün karşıllı̆ı olarak da kullanılmaktadır. Bu iki ağızda ön ses y->dc- dönüşümü yaygındır. $y->d c-$ dönüşümüyle ortaya çıkan dc- çift ünsüzündeki "c" unsuru kimi zaman kaybolur ve ön ses y-"nin karşılığı olarak palatal d'- sesi ortaya çıkar. Ön seste d'- ünsüzünün kullanımı Mordva-Karatay ağzında daha yaygındır (Alkaya 2014: 69). Çistay, Döbyaz ve İçkin ağızlarındaki kullanımı sınırlıdır.

Mor.-Kar. d'eş "genç”, d'iy- "yı̆̆g-, topla-", d'il "yel, rüzgâr”, Çis. d'in- "yen-”, d'it- "yet, ulaş-” (MTT, 69), Döb. d'ımırqa "yumurta” (TXS I, 24), İçk. d'ir "yer” (US, 245).

\section{5. Ön seste $y$->z- değişmesi}

Bu ses değişimi Orta (Kazan) grubu ağızlarından Döbyaz, Mamadış, Layış, Kazan Ardı Kreşinleri, Tüben Kama Kreşinleri, Minzele, Krasnoufim, Turbasl, Safakül; Mişer grubu ağızlarından da Temnikov, Melekes, Sterlitamak, Çüpreli, Baykıbaş, Çistay, Tatarşçino (Kürşi) ağızlarında seyrek olarak görülmektedir. Bu ses değişimi y->c- üzerinden gerçekleşmektedir. İlgili ağızlarda önce $y->c->d z-$ değişimi meydana gelmiş, ardından /d/ sesi zayıflayıp eriyince ortaya y->z- değişimi çıkmıştır (Alkaya 2014: 179; (Bayazitova vd., 2008a: 43).

Döb. zidi "yedi, 7”, (ETD, 37), Mam. zöri- "yürü-" (TXS I, 31), Lay. zasa- (ed. yasa-) "yap-” (TXS I, 43), Kaz. Ard. Krş. zırla- "türkü söyle-”. (GTK, 204), Tüb. Kam. Krş. zıyıl- 
"ylğıl-, toplan-" (GTK, 224), Min. zuq “yok" (TXS I, 219), Kra. ziber- "gönder-”. (TXS I, 304), Tur. zaz "bahar" (TXS I, 350), zizi "yedi, 7” (ST, 77).

Tem. ziyıl- "yığıl-, toplan-". (TXS II, 15), Mel. zil “yel” (TXS II, 99), Ste. zidi (TXS II, 130) "yedi, 7”, Çüp. zey- "yay-, ser-" (MTT, 179), Çis. zir (ETD, 101) “yer”, Kür. zırt "yurt, ev” (MTT, 179), Bay. zıyıl- "yığıl-, toplan-” (TXS II, 241).

\section{6. Ön seste $y$->z' - değişmesi}

Mişer grubu ağızlarından Çistay ağzında çok seyrek görülen bir ses değişimidir. Komşu ağızların ve edebî dilin etkisiyle palatal d'z'- çift ünsüzü kullanım aktifliğini yitirmekte ve d'z'sesi z'- olarak da görülmektedir. Böylece y->z'- değişimi ortaya çıkmaktadır:

Çis. z'aylı "uygun”, z'iyılış “toplanma, toplantı". (TXS II, 226).

\section{7. Ön seste $y$->j- değişmesi}

Daha çok Orta (Kazan) grubu ağızlarında seyrek ve bölgesel olarak görülen bir ses değiş̧mesidir. $\mathrm{Bu}$ değişim c- üzerinden ( $\mathrm{y}->\mathrm{c}->\mathrm{j}) \mathrm{c}$-'nin bütünüyle sızıcılaşmasıyla gerçekleşir. Krasnoufim (Yaman-Yılga, Bugalış-Tamak, Urta Bugalış, Erte-Şigiri, Ufa-Şigiri köyleri), İçkin (Tag1l ve Tarsuk köyleri), Tipikey, Esterxan (Kartuzan köyü) gibi Orta (Kazan) grup ağızlarıyla Mişer ağızlarından Kostroma ağzında görülmektedir: Kra. jılan "yılan" (US, 32), İçk. jurğan "yorgan" (US, 245), Tip. jidi “yedi, 7” (TXS I, 360), Est. jıy- "yığ-, topla-". (TXS I, 412), Kos. jayma "ince açılmış ekmek, lavaş" (MTT, 81).

Krasnoufim, İçkin, Tipikey ağızlarının konuşulduğu bölgeler coğrafi olarak Başkurdistan'a yakın yerlerdir. Başkurt Türkçesinde ön seste $y->j$ - değişimi olmasa da bilhassa alıntı kelimelerde iç seste -c->-j- değişimi görülür: heji ( $<$ hac1), hejet (<hacet), baja "bacanak", xuja (<hoca) "sahip, efendi" (Dmitriyev, 1948: 20). y->j- değişimi de c- üzerinden olduğu için bir Başkurt Türkçesi etkisi düşünülebilir.

\section{Sonuç}

Tatar Türkçesi yazı dili ön seste y- ve- c- sesini bir arada bulundurmasıyla diğer Türk lehçelerinden farklılık göstermektedir. Bu durum diğer Türk lehçelerinin etkisinden ziyade Tatar Türkçesinin iç yapısından kaynaklanmaktadır. İdil Bulgarlarına ait mezar taşlarında da görüldügü gibi o dönemde ön seste hem y- hem de c-'nin bulunduğu ağızlar söz konusudur. Kıpçakça için ön seste hem y- hem de c-'li kullanımlar DLT'de de görülmektedir. Bu durum bugün de Tatar ağızlarının ön seste y- (Mişer ve Sibirya grubu ağızları) ve c- (Orta grup ağızları) seslerinin bir arada bulundurmasılya anlaşılmaktadır.

Gerek tarihî dönemlerde gerekse günümüz Tatar yazı dilinde ve ağızlarında ön seste ysesi c- sesine göre daha fazla kullanım alanı bulmuştur. Tatar Türkçesi ağızlarında ön seste y-, c- kullanımının belirgin olduğu ağızlar olmakla birlikte ağızlar arasındaki etkileşmeler ve geçişler sebebiyle her ikisinin bir arada kullanıldığı ağızlar da söz konusudur. Ayrıca y- sesinin c-'ye dönüşmesiyle c- üzerinden dc-, d'c'-, dz-, dz'-, d'z'-, tç- gibi birleşik sesler ve bu seslerin tekleşmesiyle de c', ç, d, d', z, z', j- gibi normal veya palatal sesler ortaya çıkmıştır.

Tarihî dönemlerdeki Tatar edebî diline ait eserlerde y- sesinin c- sesine göre daha yaygın olarak kullanıldığı görülmektedir. 20. yüzyıla kadar devam eden bu durum, 1917 Bolşevik ihtilalinden sonra değişikliğe uğramıştır. Yazı dilinin halk diline ve ağızlarına yaklaştırılması düşüncesinden yola çıkılarak yazı dilinin fonetik kurallarının Orta gruba ait Kazan Ardı ağızlarına dayandırılması sonucunda tarihî yazı dilinde yaygın olan ön ses y-'nin kullanımı daralarak c- sesi aktifleştirilmiştir. Böylece Türkçe kelimelerde ön seste y- çoğunlukta olmakla birlikte c-'li kullanımlar da artmıştır. Sonuç olarak bugün Tatar yazı dilinde birlikte 
görülen ön seste y-/c- kullanımı, Tatar Türkçesinin tarihî ve çağdaş dönemlerinde bulunan bir ses özelliğinin 20. yüzyılda biraz da müdahaleyle yazı diline yansımış/yansıtılmış durumundan ibarettir.

\section{Kaynaklar}

ALKAYA, Ercan (2008). Sibirya Tatar Türkçesi. Ankara: Turkish Studies Yay.

ALKAYA, Ercan (2014). Mişer Tatar Türkçesi. İstanbul: Kesit Yay.

ARGUNŞAH, Mustafa -Gülden SAĞOL YÜKSEKKAYA-Özcan TABAKLAR (2010). Karahanlica, Harezmce, Klpçakça Dersleri. İstanbul: Kesit Yay.

ARGUNŞAH, Mustafa-Galip GÜNER (2015). Codex Cumanicus. İstanbul: Kesit Yay.

ARIKOĞLU, Ekrem (2007a). Hakas Türkçesi. Türk Lehçeleri Grameri (Ed. Ahmet B. Ercilasun). Ankara: Akçağ Yay., s. 1085-1148.

ARIKOĞLU, Ekrem (2007b). Tuva Türkçesi. Türk Lehçeleri Grameri (Ed. Ahmet B. Ercilasun). Ankara: Akçağ Yay., s. 1149-1228.

ARSLANOV, L. Ş. (1991). Osobennosti Govora Mordv1-Karatayev, Mordva-Karatay: Yazlk i Folklor, Kazan.

BAYAZITOVA, F. S. (2003). Tatar Mişer Ruxi Mirası. Saransk.

BAYAZITOVA, F. S. vd. (2008a). Tatar Xalık Söyleşlerĭ I. Kazan.

BAYAZİTOVA, F. S. vd. (2008b). Tatar Xalık Söyleşleri III. Kazan.

BURAN, Ahmet - Ercan ALKAYA (2014a). Çağdaş Türk Yazı Dilleri II, Güneydoğu/Karluk Grubu. Ankara: Akçağ Yay.

BURAN, Ahmet - Ercan ALKAYA (2014b). Çağdaş Türk Yazı Dilleri III, Kuzeybatı/Kıpçak Grubu. Ankara: Akçağ Yay.

BURAN, Ahmet - Ercan ALKAYA- Mehmet ÖZEREN (2014). Çağdaş Türk Yazı Dilleri IV, Kuzeydoğu Grubu. Ankara: Akçağ Yay.

BURAN, Ahmet - Ercan ALKAYA-S. Kaan YALÇIN (2014). Çağdaş Türk Yazı Dilleri I, Güneybatı/Oğuz Grubu. Ankara: Akçağ Yay.

CELEY, L. (1947). Tatar Dialektologiyesĭ. Kazan.

CELEY, L. (1954). Tatar Tĭlinì Tarixi Fonetikası Buyınça Materiallar. Kazan.

DMITRIYYE, N. K. (1948). Grammatika Başkirskogo Yazıka. Moskva-Leningrad.

ERCILASUN, Ahmet B. (2004). Başlangıçtan Yirminci Yüzyıla Türk Dili Tarihi. Ankara: Akçă̆ Yay.

ERCILASUN, Ahmet B. (2007 ). Köktürkçe ile Tatar Türkçesi Arasındaki Benzerlikler. Makaleler (Yay. Haz. Ekrem Arıkoğlu). Ankara: Akçağ Yay., s. 113-118.

ERSOY, Feyzi (2007). Çuvaş Türkçesi. Türk Lehçeleri Grameri (Ed. Ahmet B. Ercilasun). Ankara: Akçağ Yay., 1285-1340.

EXETOV, G. X. (1984). Tatar Dialektologiyesĭ. Kazan.

GÜLSEVİN, Gürer (2016). 11. Yüzyılda Hangi Oğuz Diyalektleri Vardı? Bilig. Kış, S. 76, s. 269-300. 
KÂŞGARLI MAHMUD (2014). Dîvânu Lugâti't-Türk (Haz. Ahmet B. Ercilasun-Ziyat Akkoyunlu). Ankara: TDK Yay.

KİIŞ̧ÇiOĞLU, M. Fatih (2007). Saha Türkçesi. Türk Lehçeleri Grameri (Ed. Ahmet B. Ercilasun). Ankara: Akçağ Yay., 1229-1284.

KORKMAZ, Zeynep (1973). Marzubān-nāme Tercümesi (İnceleme-Metin-SözlükTipkıbasım). Ankara.

MAXMUTOVA, L. T. (1978). Opıt İssledovaniya Tyurskix Dialektov, Mişarskiy Dialekt Tatarskogo Yazıka. Moskva.

MEXMUTOVA, L. T. -N. V. BORHANOVA (1969). Tatar Tĭlinĭ Dialektologik Süzlïg $\check{i}$. Kazan.

ÖZYETGIN, A. Melek (2001). Ebū Hayyān Kitābu'l-İdrāk li Lisāni'l Etrāk. Fiill: Tarihî-Karşılaştırmalı Bir Gramer ve Sözlük Denemesi. Ankara: KÖKSAV.

SEREBRENNIKOV, B. -N. GADJIEVA (1979). Sravnitelno-İstoriçeskaya Grammatika Tyurkskix Yazıkov. Baku. Yay.

TEKIN, Talât (1988). Volga Bulgar Kitabeleri ve Volga Bulgarcası. Ankara: TDK

TOPRAK, Funda (2003). Divanü Lugati't-Türk’te Kıpçakça Kaydıyla Verilen Kelimelerin Tarihi Kıpçak Söz Varlığı İçindeki Yeri. Türkoloji Dergisi. C. XVI, S. 2. Ankara, s. 79-90.

TUNA, Osman Nedim (1960). Köktürk Yazılı Belgelerinde ve Uygurcada Uzun Vokaller. TDAY-B, s. 213-282.

XAKOV, Vaxit (2003). Tĭl-Tarix Közgĭš̆. Kazan.

YUSUPOV, F. Y. (2003). Tatar Teleney Dialektları Ural Söyleşlerĭ. Kazan.

ZEKIYYV, M. Z. (1998). Törki-Tatar Etnogenezı. Kazan-Moskova.

\section{Kisaltmalar}

ETD: G. X. Exetov (1984). Tatar Diyalektologiyesi. Kazan. Moskva.

GTK: F. S. Bayazitova (1986). Govorı Tatar-Kryaşen v Sravnitelnom Osveşçenii.

TXS I: F. S. Bayazitova vd. (2008). Tatar Xalık Söyleşleri I. Kazan.

TXS II: F. S. Bayazitova vd. (2008). Tatar Xalık Söyleşleri II. Kazan.

ST: F. Y. Yusupov (2013). Safakül Tatarları Ütkeni hem Bügingiši. Kazan.

STT: Ercan Alkaya (2008). Sibirya Tatar Türkçesi. Ankara: Turkish Studies Yay. Kazan.

MTD 1974: L. T. Maxmutova (Red.) (1974). Materialı po Tatarskoy Dialektologii.

MTT: Ercan Alkaya (2014). Mişer Tatar Türkçesi. İstanbul: Kesit Yay.

US: F. Y. Yusupov (2003). Tatar Telenen Dialektları Ural Söyleşlerĭ. Kazan.

Yosıpov 2015: F. Y. Yosıpov (2015). Nagaybek Tatarları Söyleşinĭ Fonetik Üzinçelikleri Turında. Fenni Tatarstan. 2015, C. 1, S. 4, s. 9-18. 